\title{
Piezoresistive Feedback Control of a MEMS Thermal Actuator
}

Robert K. Messenger

Brigham Young University - Provo, rob.messenger@byu.edu

Quentin Theodore Aten

Brigham Young University - Provo, quentinaten@yahoo.com

Timothy W. McLain

Brigham Young University - Provo, mclain@byu.edu

Larry L. Howell

Brigham Young University - Provo, lhowell@byu.edu

Follow this and additional works at: https://scholarsarchive.byu.edu/facpub

Part of the Mechanical Engineering Commons

\section{Original Publication Citation}

Messenger R., Aten, Q., McLain, T., and Howell, L. Piezoresistive Feedback Control of a MEMS Thermal Actuator, Journal of Microelectromechanical Systems, vol 18, no. 6, pp. 1267-1278, 2009.

\section{BYU ScholarsArchive Citation}

Messenger, Robert K.; Aten, Quentin Theodore; McLain, Timothy W.; and Howell, Larry L., "Piezoresistive Feedback Control of a MEMS Thermal Actuator" (2009). Faculty Publications. 1535.

https://scholarsarchive.byu.edu/facpub/1535

This Peer-Reviewed Article is brought to you for free and open access by BYU ScholarsArchive. It has been accepted for inclusion in Faculty Publications by an authorized administrator of BYU ScholarsArchive. For more information, please contact ellen_amatangelo@byu.edu. 


\title{
Piezoresistive Feedback Control of a MEMS Thermal Actuator
}

\author{
Robert K. Messenger, Quentin T. Aten, Timothy W. McLain, and Larry L. Howell
}

\begin{abstract}
Feedback control of MEMS devices has the potential to significantly improve device performance and reliability. One of the main obstacles to its broader use is the small number of on-chip sensing options available to MEMS designers. A method of using integrated piezoresistive sensing is proposed and demonstrated as another option. Integrated piezoresistive sensing utilizes the inherent piezoresistive property of polycrystalline silicon from which many MEMS devices are fabricated. As compliant MEMS structure's flex to perform their functions, their resistance changes. That resistance change can be used to transduce the structures' deflection into an electrical signal. The piezoresistive microdisplacement transducer (PMT) is a demonstration structure that uses integrated piezoresistive sensing to monitor the output displacement of a thermomechanical inplane microactuator (TIM). Using the PMT as a feedback sensor for closed-loop control of the TIM provided excellent tracking with no evident steady-state error, maintained the positioning resolution to $\pm 29 \mathrm{~nm}$ or less, and increased the robustness of the system such that it was insensitive to significant damage.
\end{abstract}

\section{INTRODUCTION}

Closed-loop feedback control of dynamic systems is useful in improving system performance and reliability. Researchers have applied feedback control to MEMS devices [1]-[10], but one of the major challenges to the effective application of closed-loop control to MEMS is the feedback sensor. It is difficult to monitor the performance of many MEMS devices due to their micro-scale size. This paper presents a system composed of a thermal actuator mechanically coupled to a compliant piezoresistive sensing structure. The changing resistance of the structure is used as the feedback sensor monitoring the thermal actuator's output displacement. This system demonstrates that compliant piezoresistive devices can produce signal-to-noise ratios appropriate for feedback control, and that simple feedback control schemes can result in significant performance and reliability improvements for MEMS.

Some MEMS can be monitored through their output. For example, many optical MEMS produce an output that is easily observable [1], [11]-[13]. Other systems do not produce such macro-scale output. In some research environments an optical sensor such as a laser doppler vibrometer is used to measure micro or nano-scale displacements for feedback control [3], [14].

Commonly, on-chip MEMS position sensors exploit capacitive [3], [7], [15] or piezoresistive [16], [17] effects. Capacitive sensors can be difficult to implement in surface micromachined devices because of the sensing electrodes' small (much less

The authors are with the Compliant Mechanisms Research Group, Department of Mechanical Engineering, Brigham Young University, Provo, UT 84602 than $1 \mathrm{~mm}^{2}$ ) surface area. The sensors therefore produce small changes in capacitance, on the scale of femtofarads, that are difficult to detect in the presence of parasitic capacitance [3]. The piezoresistive sensing utilized in this study differs from the traditional approach because no additional process steps are required to create a piezoresistive region. Typically, onchip piezoresistive sensing is achieved by selectively doping or depositing a piezoresistive current path in a region that experiences high compressive or tensile stress when the device displaces [17]-[20].

The sensor in this study is a compliant device in which the entire structure is piezoresistive. Such uniformly doped, compliant, piezoresistive sensors can be fabricated as an integral element of a MEMS actuator. Though applied to a thermomechanical inplane microactuator (TIM) in this research, the broader concepts of an integrated piezoresistive sensor and the use of piezoresistance in feedback control can be extended to other thermal or electrostatic MEMS actuators.

\section{A. Piezoresistivity of polysilicon}

The resistivity of a piezoresistive material is a function of the stress it is experiencing. For semiconductors, the piezoresistive effect is large - up to two orders of magnitude larger than for metals [21]. The piezoresistive properties of polycrystalline silicon [22], [23] form the basis for a variety of MEMS sensors such as accelerometers [24], [25] and pressure sensors [17], [26].

As stated earlier, a method for employing piezoresistivity in MEMS devices is to use additional process steps to selectively dope or deposit specific piezoresistive regions on the device. Those doped regions become isolated piezoresistive elements that ideally monitor the strain of the most stressed parts of the device. However, it is also possible to fabricate piezoresistive MEMS by patterning uniformly doped polysilicon layers ${ }^{1}$. By carefully designing a compliant mechanism to form a current path through its compliant flexures, which are fabricated from these uniformly doped polysilicon layers, the sensing functionality is integrated into the entire device. This is referred to as integrated piezoresistive sensing because it does not require "attaching" a separate sensing element through selective doping.

\section{B. Thermomechanical inplane microactuator}

The Thermomechanical Inplane Microactuator (TIM) is used in this work to demonstrate piezoresistive feedback

\footnotetext{
${ }^{1}$ Standard surface micromachining processes such as MUMPs [27] and SUMMiT [28] use uniformly doped polycrystalline layers.
} 


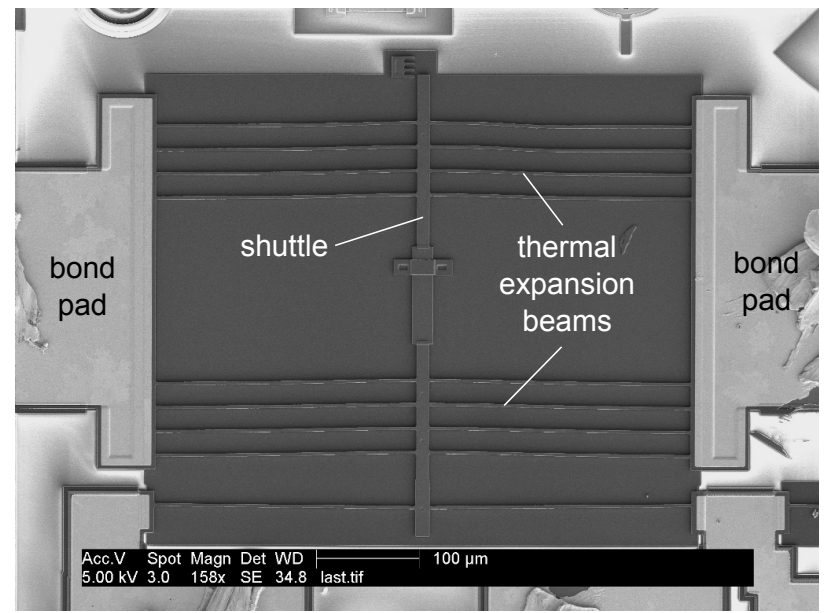

(a) No voltage applied

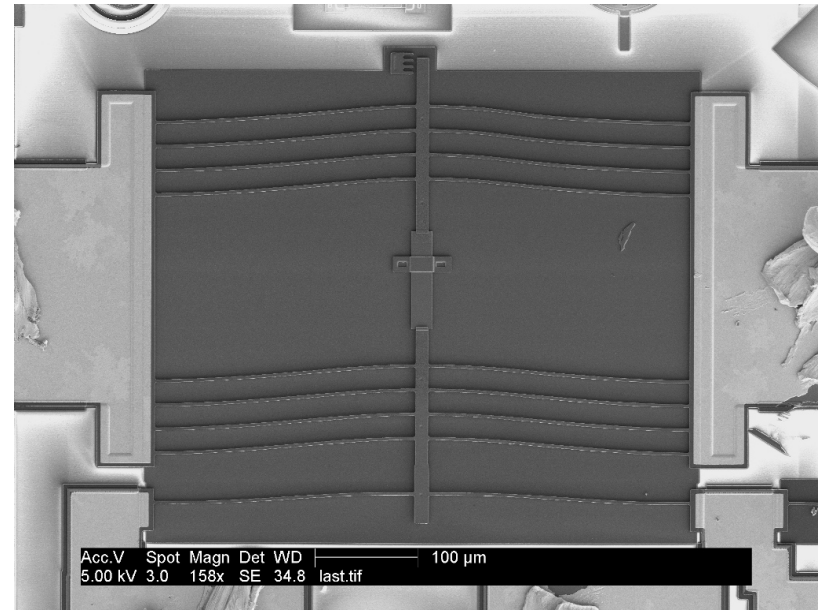

(b) Voltage applied

Fig. 1: Thermomechanical Inplane Microactuator (TIM) shown as fabricated and actuated.

control of a MEMS actuator. Piezoresistive feedback control is applicable to other MEMS thermal or electrostatic actuators, though these applications are not discussed here.

The TIM is an actuator that amplifies thermal expansion to produce a linear output force in the plane of the substrate [29]-[33]. It is constructed by suspending a shuttle off of the substrate with two symmetric arrays of thin beams. These beams are inclined in the direction of desired displacement in a bent-beam or chevron shape. The beams are attached to bond pads which are anchored to the substrate as shown in Figure 1a.

A voltage is applied across the two bond pads, which induces a current through the thin beams. The current generates ohmic heating, and as the temperature of the beams rise they expand. The lengthening of the beams causes them to buckle, and this buckling displaces the shuttle in the desired direction as shown in Figure 1b. The geometry of the TIM causes the relatively small increases in beam length to be amplified into relatively large displacements of the center shuttle.

The TIM has many characteristics that make it suitable for a variety of MEMS applications. The TIM's robust, reliable operation is realized through geometry that can be fabricated in a single layer. It is capable of producing output forces in the millinewton range and displacements on the order of $10 \mu \mathrm{m}$ using voltages on the order of 5-10 V [16], [29], [34]-[36].

The output force and displacement characteristics of thermal microactuators make them ideally suited to meeting the actuation requirements of compliant bistable devices [29], [36][38]. They have also been used to power variable optical attenuators [13], [39], and RF switches [40], [41]. Additionally, thermal actuators have been shown to be a stable and repeatable actuator for MEMS nanopositioning applications [42]. The physics of thermal actuator operation are well understood with accurate and accessible models available to aid in device and control design [31]-[33], [43].

Simplified mathematical models of thermal actuators using lumped elements and constant thermal properties do not generally match well with experimental data [31], [33]. The

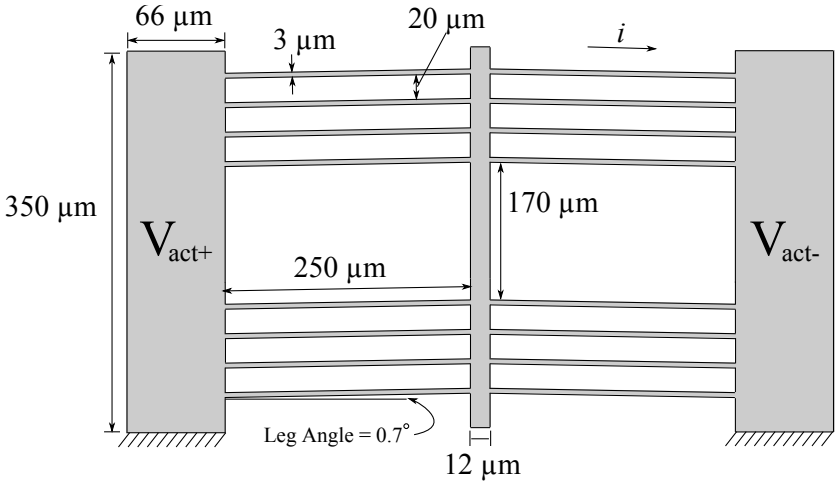

Fig. 2: Dimensioned schematic of the thermomechanical inplane microactuator (TIM) used in this research.

high temperature gradients that enable thermal actuators to work require that an accurate model incorporate temperaturedependent thermal and electrical properties. The long thin expansion beams also require a distributed solution to the thermal simulation. Given this nonlinear distributed problem, finite-difference [31] or finite-element [32], [44] solutions are appropriate.

The TIM used in this study was fabricated using the polyMUMPs prototyping service [27]. The beams and shuttle are made in the poly1 and poly2 layers laminated together for a total out-of-plane thickness of $3.5 \mu \mathrm{m}$. This maximizes the available beam aspect ratio thus inhibiting out-of-plane motion. A poly0 structure is used under the TIM to mitigate stiction. Figure 2 shows a dimensioned schematic of the TIM used in this study. The expansion beams are $250 \mu \mathrm{m}$ long, $3 \mu \mathrm{m}$ wide (in-plane), $3.5 \mu \mathrm{m}$ thick (out-of-plane), and angled by 0.7 degrees. The TIM uses two groupings of expansion legs, each with four legs. Within each group, the legs are spaced $20 \mu \mathrm{m}$ apart, and there is $170 \mu \mathrm{m}$ between leg groups. The TIM has an electrical resistance of approximately $300 \Omega$.

An examination of the finite-element simulation for this TIM predicts a safe maximum displacement of about $10 \mu \mathrm{m}$. 


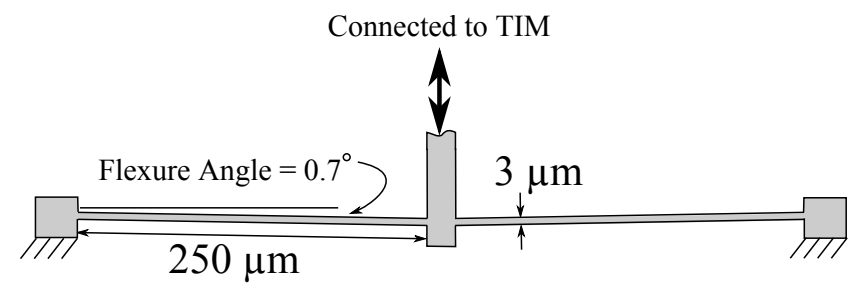

Fig. 3: Dimensioned schematic of one pair of piezoresistive microdisplacement transducer (PMT) flexures.

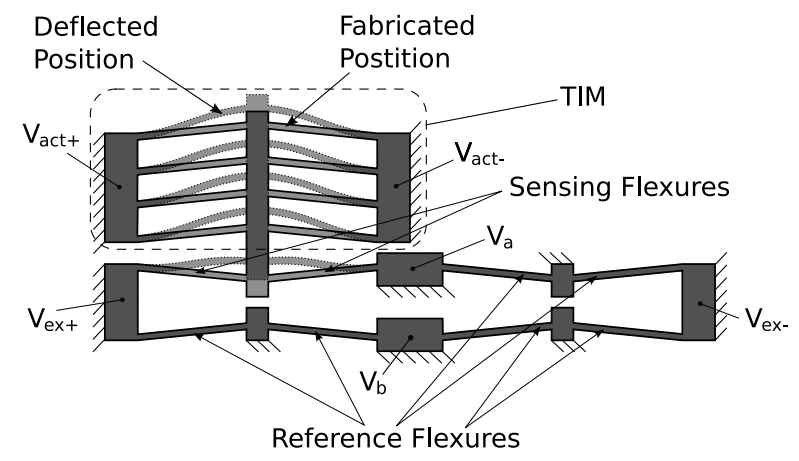

Fig. 4: Physical schematic of the thermomechanical inplane microactuator/piezoresistive microdisplacement transducer setup.

It also predicts a $400 \mathrm{~Hz}$ bandwidth for the thermal response. This is orders of magnitude below the mechanical natural frequencies reported by Hickey et al. [33] and Messenger et al. [44] which are around $100 \mathrm{kHz}$.

\section{Piezoresistive Microdisplacement Transducer}

The piezoresistive microdisplacement transducer (PMT) [45] used in this study employs a pair of sensing flexures that is similar to the beam pairs of the TIM. As shown in Figure 3, the flexure pair is fabricated identically to a TIM beam pair, except that it is inclined in the opposite direction. The PMT's initial resistance is $2.4 \mathrm{k} \Omega$. The sensor uses $3.7 \mathrm{~mW}$ when using a $3 \mathrm{~V}$ excitation across the bridge.

Figure 4 illustrates the TIM/PMT layout, and how it functions. As the flexure pair is displaced it experiences increasingly greater stresses, as shown in Figure 5. As a result of their inherent piezoresistivity, the sensing flexures' electrical resistance increases as the stress increases. The sensing flexures along with three fixed reference flexure pairs form the legs of a Wheatstone bridge, shown schematically in Figure 6. The output of the bridge is the electric potential difference between $V_{a}$ and $V_{b}$, which is a function of the bridge excitation voltage $\left(V_{e x}\right)$ and the resistances of the bridge legs (flexure pairs). The result is that the displacement of the TIM can be inferred from the output voltage of the PMT. A scanning electron micrograph (SEM) of the TIM and PMT is shown in Figure 7.

Using reference flexures in the Wheatstone bridge not only allows for a well balanced bridge, but also provides thermal compensation. The temperature profile of the PMT can be modeled the same way a thermal actuator is modeled. Heat

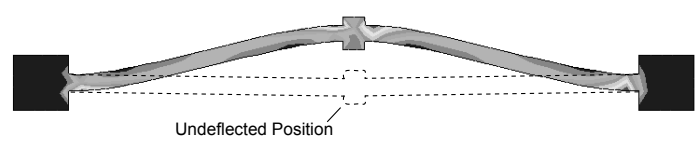

Fig. 5: Finite-element-analysis displaying the Von Misses stress distribution of piezoresistive microdisplacement transducer sensing flexures as they are displaced toward the top of the page.

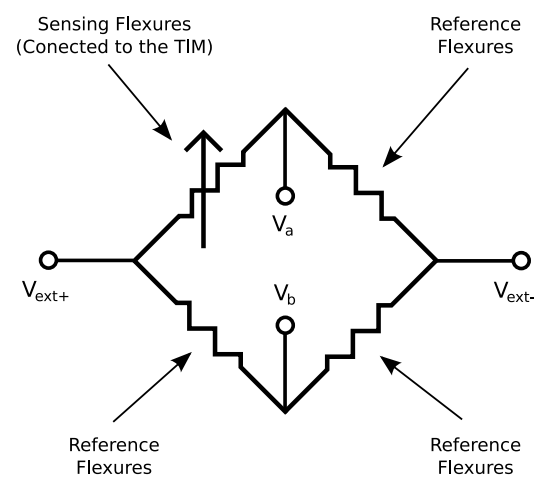

Fig. 6: Electrical schematic of the piezoresistive microdisplacement transducer.

transfer models that have been developed for MEMS thermal actuators [31], [32], [44], [46] show that the temperature profile of a long thin beam with current running through it is dominated by the internal ohmic heat generation and the large thermal sink of the substrate that is in close proximity to the beam. Based on these previous modeling results, we predict temperature changes in the PMT are predominantly due to ohmic heating from the excitation voltage. Standard analog circuitry is sufficient for any signal conditioning because of the DC nature of the sensor output voltage.

With a $3 \mathrm{~V}$ excitation the PMT outputs approximately $1 \mathrm{mV}$

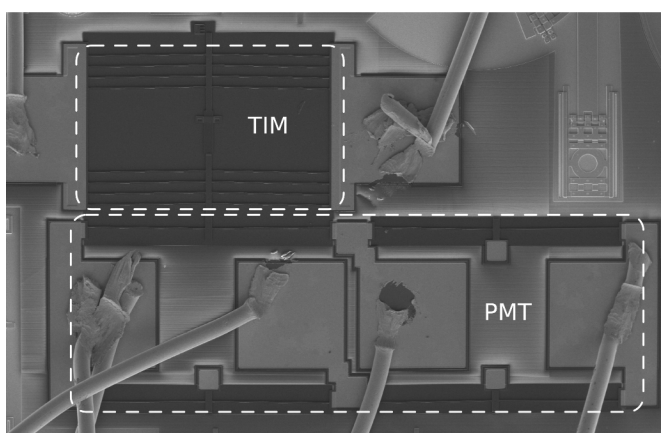

Fig. 7: Scanning electron micrograph of the thermomechanical inplane microactuator/piezoresistive microdisplacement transducer setup. 
per $\mu \mathrm{m}$ of displacement. To remove any common-mode interference from the TIM actuation voltage, the Wheatstone bridge was excited using a floating power supply and the output voltage was measured using an instrumentation amplifier. ${ }^{2}$ The analog signal conditioning circuitry compensated for the DC bias from the Wheatstone bridge to give $0 \mathrm{~V}$ from the PMT at $0 \mathrm{~nm}$ TIM displacement. Additionally, the signal was amplified further (total gain of 1000) and low-pass filtered with a $37 \mathrm{kHz}$ second-order Butterworth filter for dynamic performance measurements, or filtered with a $20 \mathrm{~Hz}$ secondorder Butterworth filter for steady-state sensor characterization and positioning measurements. Unless otherwise noted, all of the data reported reflect this signal conditioning.

When compared to the output force of the TIM, the PMT does not require a significant force to displace. FEA modeling of the structure, including thermal expansion forces, predict that $15 \mu \mathrm{N}$ are required to displace the PMT $5 \mu \mathrm{m}$. A TIM with these dimensions can provide approximately $300 \mu \mathrm{N}$ at that displacement [47]. The PMT does not significantly alter the dynamics of the TIM. TIM dynamics are dominated by the heat transfer dynamics of the thermal expansion beams, and the heat transfer of the expansion beams is not significantly affected by proximity to the PMT.

\section{A. Piezoresistive response of the PMT}

Doping concentrations for MUMPs are not controlled well. They are typically about $10^{19}$ phosphorus atoms $/ \mathrm{cm}^{3}$. Even though the exact piezoresistive response cannot be calculated due to variations in dopant concentrations, it is desirable to predict the general form of the response. The linear model of piezoresistance [48] has been shown to correctly predict changes in resistance due to uniaxial loading but not for flexures experiencing more complex loading [23], [49].

Messenger [50] developed a piezoresistive flexure model that estimates fractional change in resistance for a long thin polysilicon beam experiencing axial and/or moment loads using experimentally derived parameters to relate stresses to changes in resistance. This model estimates the net fractional change in resistance of a beam under complex loading, in which current flows longitudinally through the beam. The model assumes that the piezoresistive response is dominated by changes in resistance due to stresses in the direction of current flow (e.g. stresses due to axial loading and the maximum tensile stresses due to an applied moment loads), while transverse shear stresses in the beam are assumed to make a negligeable contribution [23].

Planar, six degree-of-freedom beam finite elements can be used to calculate stresses due to axial loading and the maximum tensile stresses due to applied moment loads for long, thin flexures. The stresses in the PMT due to an applied displacement and thermal expansion were modeled using an Ansys 2-D, six degree-of-freedom beam element, static, nonlinear, elastic model. Given the stresses due to axial loading and the maximum tensile stresses due to applied moment loads for each beam element in the model, the net fractional change in resistance is given by

\footnotetext{
${ }^{2}$ Analog Devices AD621AN
}

$$
\frac{\Delta R}{R}=\frac{1}{n} \sum_{i=1}^{n}\left(\beta_{A} \sigma_{i, A}+\beta_{M} \sigma_{i, B}^{2}\right)
$$

where $n$ is the number of elements the beam is subdivided into, $\beta_{A}$ is the experimentally derived parameter for stresses due to axial loading, $\beta_{M}$ is the experimentally derived parameter for the maximum tensile stresses due to an applied moment load, $\sigma_{i, A}$ is the stress due to axial loading for the $i^{t h}$ element, and $\sigma_{i, M}$ is the maximum tensile stress due to applied moment loading for the $i^{t h}$ element. Summing the results from the $i^{\text {th }}$ through $n^{\text {th }}$ elements using equation 1 predicts the net fractional change in resistance of the beam experiencing the combination of axial and moment loads.

When the PMT's piezoresistive sensing beam pair is placed in a Wheatstone bridge, with three other identical, but stationary beam pairs, the Wheatstone bridge output is a function of the sensing pair's fractional change in resistance and the bridge excitation voltage

$$
V_{\text {out }}=\frac{\Delta R / R}{4+2 \Delta R / R} V_{\text {ex }} .
$$

The bridge excitation voltage $V_{e x}$ was 3 VDC in all experiments reported in this paper.

The PMT's Wheatstone bridge output is simulated in three steps. First, finite-element analysis of the PMT's sensing flexures provides the stresses due to axial loads and the maximum tensile stresses due to moment loads induced by the PMT's thermal expansion and the displacement applied by the TIM. The stresses due to axial loading are about ten times as large as the maximum tensile stresses due to applied moments bending stresses, and are significantly affected by the thermal expansion of the flexures which result from the bridge excitation voltage $V_{e x}$.

Second, these stresses are used in equation (1) to calculate the fractional change in resistance for various displacements of the PMT. From data collected for the polyMUMPs process representative values of $\beta_{A}$ and $\beta_{M}$ were taken as $\beta_{A}=$ $-122.6 \times 10^{-6} \mathrm{MPa}^{-1}$ and $\beta_{M}=2.5 \times 10^{-9} \mathrm{MPa}^{-2}$ [50], respectively.

Third, the fractional change in resistance from equation (1) is input into equation (2) to predict the bridge output voltage. The predicted PMT output versus TIM displacement is shown in Figure 8. The piezoresistive flexure model predicts a nearly linear approximation to the response of PMT for an average flexure temperature of $350^{\circ} \mathrm{C}$. The slope of the linear approximation to the response of the PMT is affected by the parameters $\beta_{A}$ and $\beta_{M}$, which in polyMUMPs can vary from fabrication run to fabrication run. Additionally, since the piezoresistance of polysilicon is temperature dependent [51] and ohmic heating in the beams results in a non-uniform temperature profile, the true values of the parameters $\beta_{A}$ and $\beta_{M}$ will vary slightly according to the sensing beams' temperature profile. These temperature-profile-induced differences in the piezoresistive coefficients are a likely source of observed non-linearity in the actual PMT output shown in Figure 8. Additionally, thermal conduction through the TIM shuttle to the PMT may also contribute to non-uniform temperature 


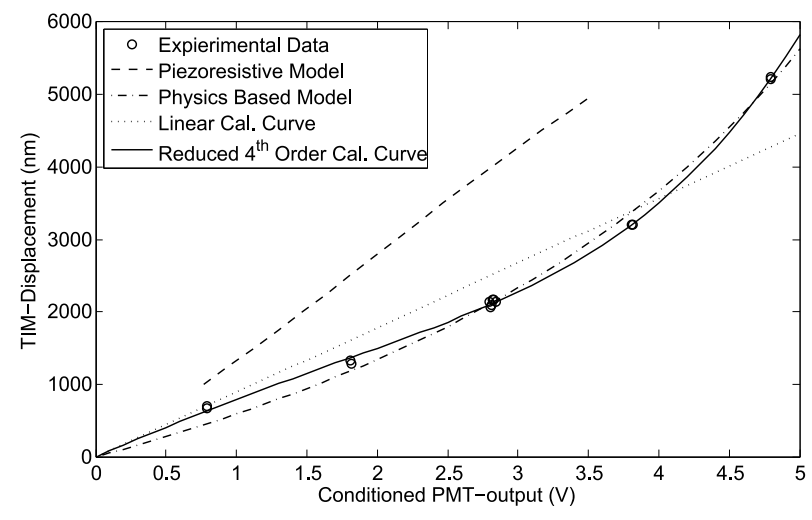

Fig. 8: Piezoresistive microdisplacement transducer (PMT) output (gain $=1000,20 \mathrm{~Hz}$ low-pass filtered) versus thermomechanical inplane microactuator (TIM) displacement. PMT output predicted by equation (1) and equation (2) is shown along with the physics-based model, the first-order calibration curve and the reduced fourth-order calibration curve.

profiles, and consequently to the observed non-linear PMT response [31].

\section{B. Sensor characterization}

The PMT is useful as a sensor because it has a specific and repeatable relationship between its resistance and its displacement. This relationship is a one-to-one mapping function such that a unique PMT output voltage corresponds to a unique displacement. To calibrate this particular TIM/PMT system, TIM displacements were measured and compared with the resulting PMT output voltages to characterize the PMT voltage-to-displacement mapping function. The displacements were measured in ambient air by taking digital images of the deflected structure using a light microscope at $1000 \mathrm{X}$ magnification. The displacements were also measured using a scanning electron microscope ${ }^{3}$ (SEM) at $7500 \mathrm{X}$ magnification. As shown in Figure 9, fiducial marks were integrated into the structure that facilitated sub-pixel measurement of the images by an image processing algorithm [43].

Significant curvature was expected from previous experience, therefore data points were taken, in random order, at five evenly spaced levels in ambient air and in the vacuum of an SEM. The model and calibration curves presented below do not include constant (offset) terms because $0 \mathrm{~V}$ from the PMT corresponds to $0 \mathrm{~nm}$ TIM displacement. Sufficient replication was used (14 total data points) to quantify the uncertainty of the regression.

The measured noise from the PMT output can be transformed into sensor repeatability using variance propagation. The measurement taken in ambient air with the largest spread had a standard deviation of $4.3 \mathrm{mV}$ (after 1000X amplification and $20 \mathrm{~Hz}$ roll-off low-pass filtering) that maps to a spread having a standard deviation of $4.7 \mathrm{~nm}$, or a $95 \%$ confidence interval of $\pm 9.1 \mathrm{~nm}$. In other words, a PMT measurement is within $9.1 \mathrm{~nm}$ of another PMT measurement that has the same output voltage.

\footnotetext{
${ }^{3}$ Philips XL30 ESEM FEG
}

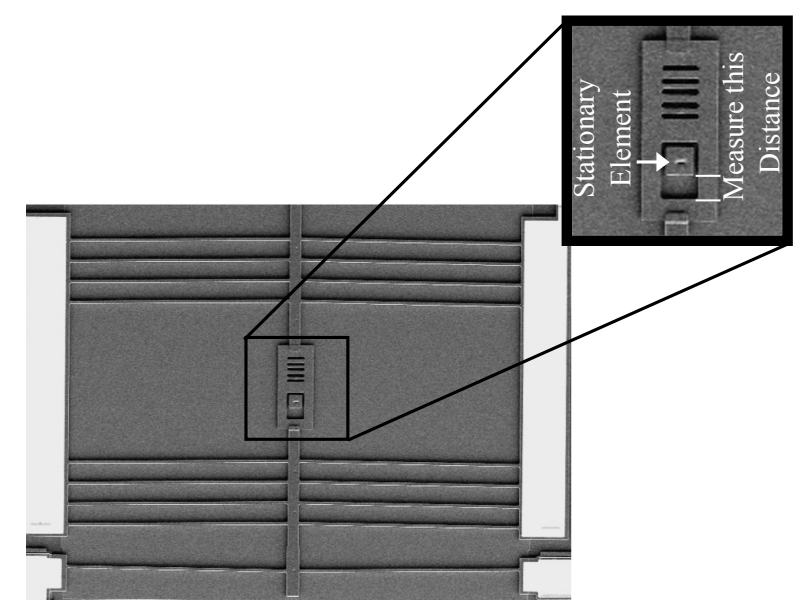

Fig. 9: Scanning electron micrograph of the fiducial structure incorporated into the thermomechanical inplane microactuator shuttle.

The vacuum environment inside the SEM significantly changes the heat transfer physics of the sensor and the actuator, resulting in greater PMT sensitivity. As a result, a smaller signal conditioning gain was required. The electrical environment inside the SEM is also noisier, requiring the more aggressive $20 \mathrm{~Hz}$ low-pass filter. The sensor repeatability, when operated in the SEM, is $\pm 12 \mathrm{~nm}$ as calculated from a variance propagation just as was done with the optical results. The degraded repeatability likely results from the noisy electrical environment inside the SEM.

For the physics-based model and the calibration curves, the residuals were used to generate confidence intervals that have a 95\% chance of containing the true system performance (TIM displacement) for a given system input (PMT voltage).

A physics-based model can be derived from the Wheatstone bridge equation. To generate this model all resistors are assumed to have the same initial resistance $R$. Additionally, the model assumes that the PMT's sensing flexure has a change in resistance of $\Delta R_{P M T}$ due to piezoresistive response and any thermal effects from the TIM. The "dummy" resistors each experience the same change in resistance of $\Delta R_{D}$ due to thermal effects from the TIM. The amplified PMT output voltage $V_{P M T}$ is then given by

$$
V_{P M T}=G\left[\left(\frac{R+\Delta R_{P M T}}{2 R+\Delta R_{P M T}}-\frac{R+\Delta R_{D}}{2 R+\Delta R_{D}}\right) V_{e x}\right]
$$

where $G$ is the signal conditioning gain and $V_{e x}$ is the bridge excitation voltage. Combining terms gives

$$
V_{P M T}=\frac{G V_{e x}}{2}\left(\frac{\Delta R_{P M T}-\Delta R_{D}}{2 R+\Delta R_{P M T}+\Delta R_{D}}\right)
$$

This model assumes that $\Delta R_{P M T}$ is proportional to some piezoresistive coefficient and displacement $\delta_{T I M}\left(\Delta R_{P M T}=\right.$ $A \delta_{\text {TIM }}$ ). The model assumes that $\Delta R_{D}$ is linearly dependent on the TIM's temperature, which is approximated by a linear dependence on the power input to the TIM, which in turn is assumed to be linearly dependent on displacement $\delta_{\text {TIM }}$ 


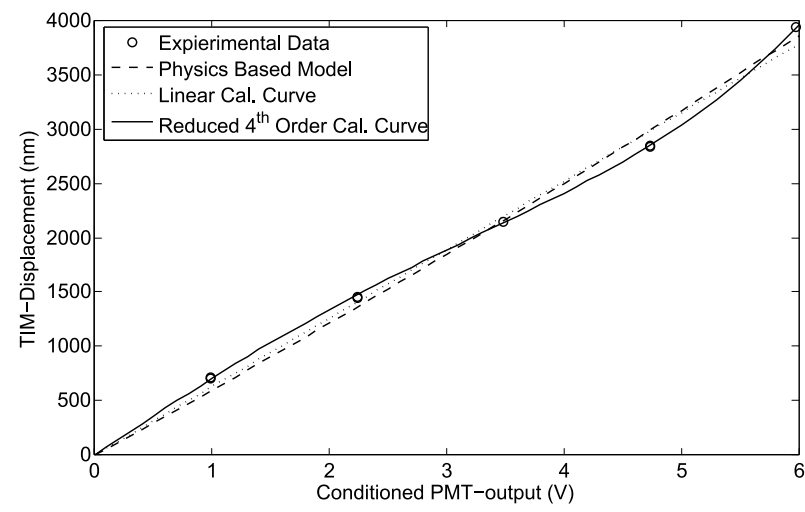

Fig. 10: Piezoresistive microdisplacement transducer output (gain $\approx 1000,20 \mathrm{~Hz}$ low-pass filtered) versus thermomechanical inplane microactuator displacement with the physics-based model, the first-order calibration curve and the reduced fourthorder calibration curve. Data taken in the vacuum environment of a scanning electron microscope.

$\left(\Delta R_{D}=B \delta_{T I M}\right)$. Making these assumptions gives

$$
V_{P M T}=\frac{G V_{e x}}{2}\left(\frac{(A-B) \delta_{T I M}}{2 R+(A+B) \delta_{T I M}}\right)
$$

The model is made more compact by $G, V_{e x}, R,(A+B)$, and $(A-B)$ terms to give

$$
V_{P M T}=\frac{C_{1} \delta_{T I M}}{\left(1+C_{2} \delta_{T I M}\right)}
$$

which can be solved for $\delta_{T I M}$ to give

$$
\delta_{T I M}=\frac{V_{P M T}}{C_{1}-C_{2} V_{P M T}} .
$$

The values of $C_{1}$ and $C_{2}$ are found by performing a non-linear least squares regression on the displacement and voltage data.

Figure 8 shows the physics-based model applied to data taken for a TIM-PMT system operating in ambient air with $C_{1}=1.889 \times 10^{-3}$ volts $\mathrm{nm}^{-1}$ and $C_{2}=1.999 \times 10^{-4} \mathrm{~nm}^{-1}$. This model has an $R^{2}$ value of 0.9914 and a maximum confidence interval width of $\pm 261 \mathrm{~nm}$. Figure 10 shows the physical model applied to data taken for a TIM-PMT system in the vacuum of and SEM with $C_{1}=1.696 \times 10^{-3}$ volts $\mathrm{nm}^{-1}$ and $C_{2}=2.367 \times 10^{-5} \mathrm{~nm}^{-1}$. This model has an $R^{2}$ value of 0.9913 and a maximum confidence interval width of $\pm 136 \mathrm{~nm}$.

Examination of the experimentally measured PMT output shown in Figures 8 and 10 reveals at least two inflection points in the PMT response which is not modeled by (7). The statistical response surface method can be used to generate empirical calibration curves for systems, such as the PMT, which are either difficult or impossible to model from first principles, but whose response to inputs is measurable. This method allows for the estimation of the coefficients for an $n-1$ degree polynomial calibration curve from measurements taken at $n$ levels. Repeated measurements at these levels allow for estimation of the measurement system and calibration curve error. Calibration curve terms, which through statistical analysis are shown to make an insignificant contribution to the calibration curve's accuracy, can be trimmed from the polynomial to produce a more parsimonious equation. [52]

While the analytically predicted response for an isothermal PMT is close to linear, the true PMT response is significantly non-linear due to the non-uniform temperature profile of the PMT and the temperature dependence of the experimentally derived parameters $\beta_{A}$ and $\beta_{M}$, as described previously. A fourth-order calibration curve will capture significant curvature due to the PMT's non-uniform temperature profile such that any deviation from the calibration curve will be measurement uncertainty. After computing the full fourth-order polynomial, the insignificant $\left(V_{P M T}\right)^{2}$ term was trimmed from the polynomial, and the calibration curve recomputed to generate a reduced fourth-order calibration curve.

Figure 8 shows the data points, a first-order linear calibration curve $\left(R^{2}=0.8855\right)$, and the reduced fourth-order calibration curve $\left(R^{2}=0.9991\right)$. The resulting reduced fourthorder calibration curve relating PMT sensor output, $V_{P M T}$, in signal conditioned volts, to TIM displacement, $\delta_{T I M}$, in nm, is

$$
\begin{aligned}
\delta_{T I M}= & (10.26) V_{P M T}{ }^{4} \ldots \\
& -(37.43) V_{P M T}{ }^{3} \ldots \\
+ & +(883.8) V_{P M T} .
\end{aligned}
$$

The regression's uncertainty is too small to illustrate clearly in the figure, but the maximum spread of the confidence interval is $\pm 93 \mathrm{~nm}$.

TIMs have demonstrated significantly better positioning repeatability than $\pm 93 \mathrm{~nm}$ [42]. Additionally, the physics governing PMT operation, as discussed previously, imply the existence of a well behaved, continuous function that maps displacement to stress and then to resistance change. It is therefore reasonable to assume a majority of the $\pm 93 \mathrm{~nm}$ uncertainty comes from the optical displacement measurements.

Figure 10 shows the data taken in the SEM, a first-order linear calibration curve $\left(R^{2}=0.9892\right)$, and the reduced fourth-order calibration curve $\left(R^{2}=0.9998\right)$. The fourthorder calibration curve relating PMT sensor output, signal conditioned for the SEM, to TIM displacement, in $\mathrm{nm}$, is

$$
\begin{aligned}
\delta_{T I M}= & (2.87) V_{P M T}{ }^{4} \ldots \\
& -(18.96) V_{P M T}{ }^{3} \ldots \\
+ & +(722.26) V_{P M T} .
\end{aligned}
$$

Once again the residuals from the reduced fourth-order calibration curve were used to determine the bounding envelope that has a $95 \%$ certainty of containing the actual TIM displacement for a given PMT output. Using the SEM for displacement measurements reduces the confidence interval's maximum spread to $\pm 20 \mathrm{~nm}$. The variable gain seen in PMT output plotted in Figure 10, specifically the reduced gain around the fourth measurement level, is most likely due to nonlinear effects arising from uneven heating of the PMT flexures.

\section{Dynamic performance}

Figure 11 is a plot comparing TIM input voltage and the resulting PMT output voltage. The square wave response reveals a time constant of $300 \mu$ s, matching the expected 

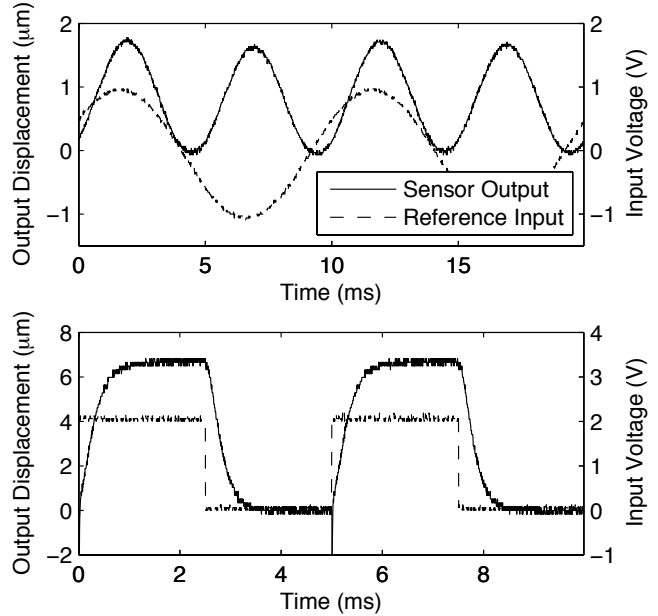

Fig. 11: Plots comparing the input voltage to the thermomechanical inplane microactuator and the resulting output voltage of the piezoresistive microdisplacement transducer (gain $=1000,37 \mathrm{kHz}$ low-pass filtered)

open-loop transient response of this TIM [32], [44], [53]. The sinusoidal input demonstrates the expected double frequency TIM response. The double frequency response is a result of the TIM physics. The TIM output displacement is a function of the expansion beam temperature, which is a function of the power into the system. The power is proportional to the input voltage squared. The trigonometric identity

$$
\sin ^{2}(x)=\frac{1-\cos (2 x)}{2}
$$

demonstrates that a squared sinusoidal input results in a vertically shifted, double frequency response. An intuitive description is that the TIM will actuate the same direction regardless of the voltage polarity.

Figure 11 also shows that the PMT produces a strong signal with low noise. The signal to noise ratio is 450 as measured by comparing a $95 \%$ confidence interval of the signal to its magnitude. The piezoresistive sensing phenomenon comes from the polysilicon band-gap energy responding to the changing inter-atomic spacing of the stressed crystalline structure. The dynamics of this phenomenon are much faster than the heat transfer dynamics of the system, or even the mechanical resonance of the device. It can therefore be assumed that the PMT does not contribute any dynamics to the output signal. The spike that is evident at the rising edge of the square wave is an electrical artifact resulting from emf interference between the larger actuating signal and the smaller sensor output at the device level. The spike happens too fast to be a physical effect of the system, and is still evident when a "dummy" system is used that has the same electrical layout without any piezoresistive output. The phenomenon is most likely parasitic capacitive coupling between the Wheatstone bridge output and the input signal to the TIM, and will be explained in greater detail in the next section.

The frequency response of the TIM/PMT system was measured to facilitate control design. Figure 12 shows the
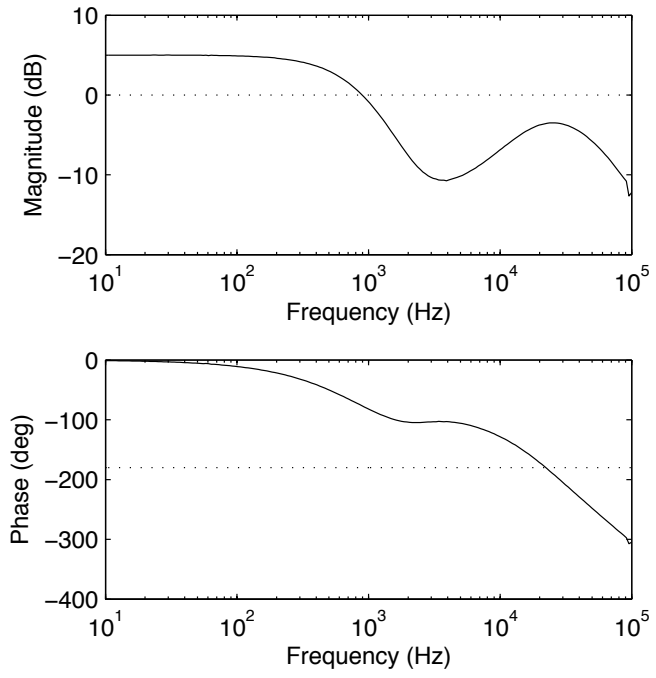

Fig. 12: Open-loop frequency response of the thermomechanical inplane microactuator/piezoresistive microdisplacement transducer system. The rise in magnitude after $5000 \mathrm{~Hz}$ is likely an electrical artifact induced by parasitic capacitance.

frequency response as measured by a spectrum analyzer connected to the TIM/PMT system (gain of 1000, $37 \mathrm{kHz}$ secondorder low-pass filter). The system was driven by a sine sweep with a signal that ranged from 0 to $3 \mathrm{~V}$. Biasing the input to include only positive voltages results in increasing displacement with increasing applied voltage rather than increasing TIM displacement with decreasing negative voltage as shown in Figure 11. The validity of using a frequency response such as this one is confirmed by coherence values of 0.997 or greater throughout the frequency range measured.

The steep magnitude drop off at about $500 \mathrm{~Hz}$ results from the heat transfer dynamics of the TIM and is close to the expected value of about $400 \mathrm{~Hz}$ that is reported in the literature [31], [32], [44]. Since the TIM/PMT frequency response is limited by the TIM's heat transfer dynamics, which is much below the TIM's mechanical resonance of approximately $100 \mathrm{kHz}$, one would expect the magnitude would continue to decrease above approximately $500 \mathrm{~Hz}$. Thus, the magnitude rise after about $5,000 \mathrm{~Hz}$ is likely due to parasitic capacitance between the Wheatstone bridge and the input signal to the TIM.

The TIM actuation signal was applied symmetrically to the expansion beams; e.g. one bond pad was at $-2 \mathrm{~V}$ and the other was at $+2 \mathrm{~V}$. In this manner the center shuttle of the TIM, and consequently the physical connection to the PMT, remained at a constant $0 \mathrm{~V}$ relative to the driving signal, ruling out direction conduction as a possible source of the interfering signal.

\section{Parasitic capacitance}

A low-order approximation of the thermal and electrical dynamics of the system provide greater confidence that parasitic capacitance is being observed. In addition it provides some insight into how to minimize the problem. The primary contribution to the output signal from the PMT is TIM 


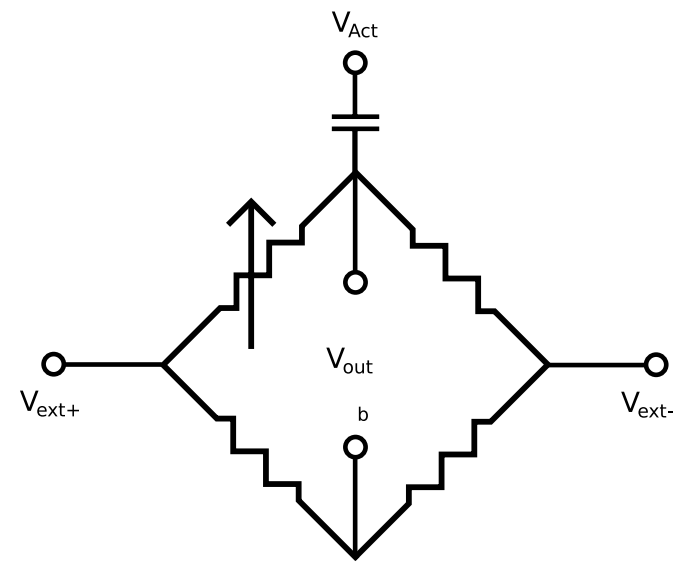

Fig. 13: A schematic describing the low-order lumped model of parasitic capacitance between the piezoresistive microdisplacement transducer and the thermomechanical inplane microactuator actuation voltage.

motion. A secondary, smaller contribution is suspected to come from parasitic capacitance. While it does not capture the distributed effects of TIM heat transfer dynamics [31], [32], [44], a first-order lumped model of the actuator provides a reasonable approximation of its behavior and allows the effects of parasitic capacitance to be analyzed. A typical first-order transfer function with a time constant of $300 \mu$ s can be used to model the dynamic behavior of the TIM:

$$
\frac{V_{\text {out }}}{V_{\text {Act }}}=\frac{1}{\tau s+1} \text {. }
$$

Parasitic capacitance is also a distributed phenomenon. The PMT structure is capacitively coupled to the TIM, the surrounding environment, and nearby electrical connections. A first-order lumped approximation is used to investigate how parasitic capacitance affects the PMT output dynamics. The parasitic capacitance is modeled by connecting one output terminal of the PMT Wheatstone bridge to the TIM actuation voltage, $V_{A c t}$, through a representative parasitic capacitor, $C$, as shown in Figure 13. The corresponding transfer function relating $V_{\text {Act }}$ to $V_{\text {out }}$ is

$$
\frac{V_{\text {out }}}{V_{\text {Act }}}=\frac{C s}{C s+1 / 2} .
$$

The parasitic capacitance acts in parallel with the actuator dynamics on the output of the sensor. In other words, the TIM actuation voltage has two paths to contribute to the PMT output dynamics. The desired transmission is the actuation voltage causing TIM motion, and that motion being measured by the changing resistance of the sensing flexures. The undesirable transmission is through the parasitic capacitance. The system dynamics can be estimated by combining the loworder approximations of these two sources of dynamics in parallel as shown in Figure 14. A low-pass filter is applied to the sensor output signal, as was done in the experimental system. The resulting frequency response is of the same form as the measured response shown in Figure 12. This leads us to believe that parasitic capacitance causes the high-frequency

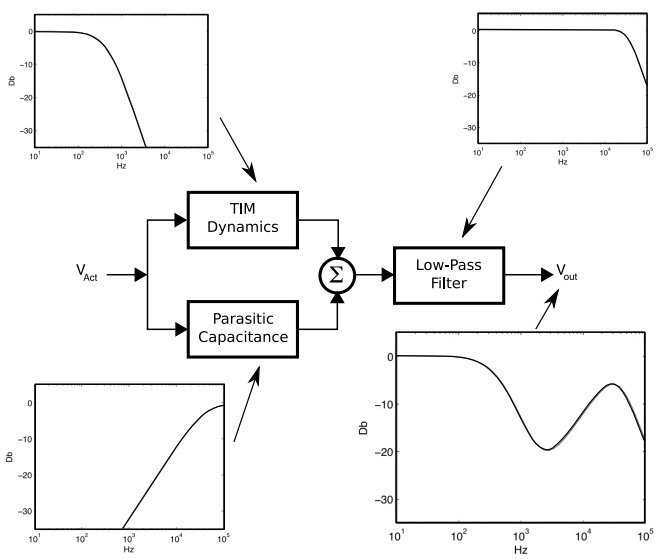

Fig. 14: Schematic showing the sources of dynamics reflected in the piezoresistive microdisplacement transducer output.

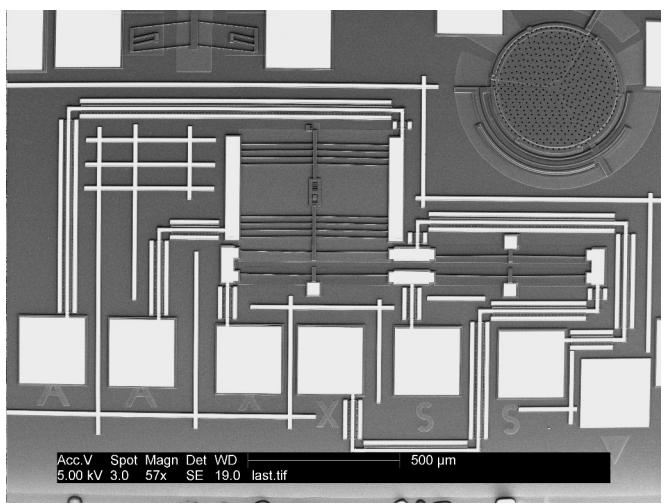

Fig. 15: A scanning electron micrograph showing the electrically grounded structures which reduce the high-frequency artifacts likely produced by parasitic capacitance.

rise in magnitude observed in the experimental system.

Experience also shows that both abnormal phenomenon observed in the PMT output (the spikes evident on the step response and the high frequency rise in magnitude on the frequency response) are mitigated by reducing the effective value of the parasitic capacitor. Isolating the electrical connections actuating the TIM and placing grounded structures between the TIM and the PMT, as shown in Figure 15, reduce both the phenomenon, further indicating the high-frequency rise and step response spikes are both likely caused by parasitic capacitance. While this parasitic capacitive phenomenon does not represent TIM motion, it does have an effect on system closed-loop stability and control design.

\section{Control Design}

The empirical frequency response shown in Figure 12 is used to design standard control laws for the TIM/PMT system. We will use the empirical data for control design because it captures accurate information about the system even under conditions where the distributed thermal and electrical dynamics are not well defined.

The control designs described below follow the standard form shown in Figure 16 where $D(s)$ represents the controller dynamics and $G(s)$ represents the system dynamics 


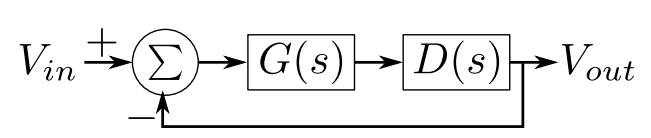

Fig. 16: Feedback control (closed loop) block diagram.

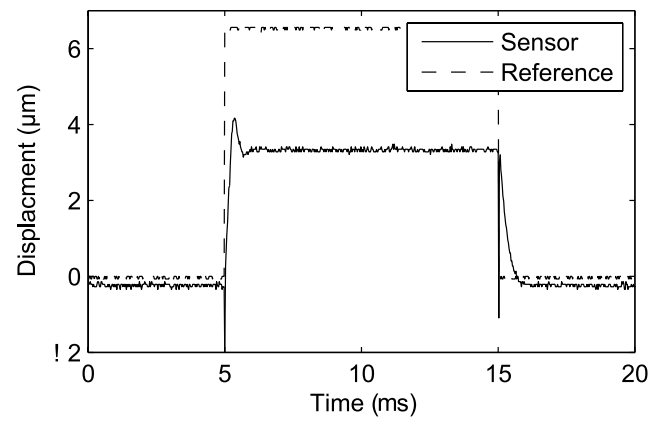

Fig. 17: Proportional-control step response (gain $=1000$, $37 \mathrm{kHz}$ low-pass filtered).

including the actuator, sensor, and signal conditioning. For this nanopositioning application, two metrics will be used to gauge performance: settling time and steady-state error.

\section{A. Proportional control}

The open-loop frequency response in Figure 12 indicates that significant transient response improvement can be achieved with simple proportional control

$$
D(s)=k_{p} .
$$

The gain $\left(k_{p}\right)$ can be increased to improve tracking performance until the high-frequency electrical artifact begins causing stability problems.

Figure 17 shows the response of the TIM under proportional control. While the initial transient response is significantly faster with proportional control, the settling times for the openloop and proportional control systems are both about $1.5 \mathrm{~ms}$.

While proportional control has desirable transient response characteristics, it results in a significant steady-state error of almost 50 percent of the step input magnitude. The steadystate error results from the heat transfer physics of the system and is expected with proportional control alone [43].

\section{B. Integral-lead control}

The steady-state error evident in the proportional control response is eliminated by an integrator in the control law. In addition, some form of derivative based dynamic control can effectively mitigate the negative effects an integrator has on the transient response. An integral-lead controller,

$$
D_{i \ell}(s)=k \frac{s+\omega_{z}}{s\left(s+\omega_{p}\right)},
$$

is formed from a lead controller modified to include integration by increasing the order of the denominator. The lead portion of the control can be tuned so that it does not amplify the high frequency electrical artifact shown in Figure 12.

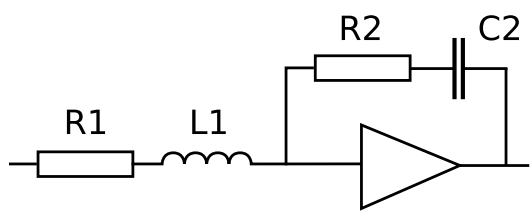

Fig. 18: Schematic of integral-lead control implementation.
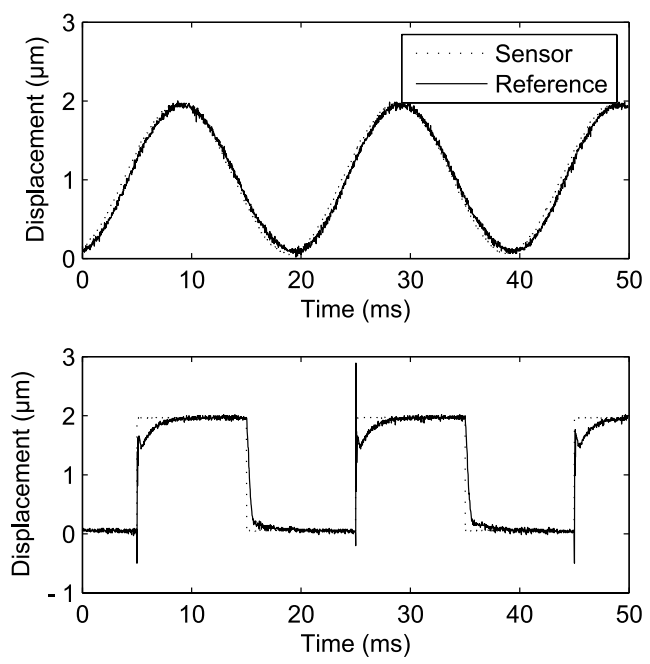

Fig. 19: Integral-lead control tracking performance (gain $=1000,37 \mathrm{kHz}$ low-pass filtered).

The integral-lead controller is implemented using a single op-amp stage as shown in Figure 18. The circuit parameters are related to the control values by the expressions

$$
\begin{aligned}
k & =\frac{R_{2}}{L_{1}}, \\
\omega_{z} & =\frac{1}{R_{2} C_{2}}, \\
& \text { and } \\
\omega_{p} & =\frac{R_{1}}{L_{1}} .
\end{aligned}
$$

The control values were selected [54], using the open-loop frequency response (Figure 12), to set the controller zero $\left(\omega_{z}\right)$ to $200 \mathrm{rad} / \mathrm{s}$, the pole $\left(\omega_{p}\right)$ to $10,000 \mathrm{rad} / \mathrm{s}$, and the gain $(k)$ equal in magnitude to the pole. These values were chosen as a compromise between rise time and overshoot. The predicted closed-loop response, of the system with integral-lead control, has a gain margin of 1.8 and a phase margin of 45 degrees.

Figure 19 demonstrates the close tracking performance achieved with integral-lead control. No steady-state error is evident, while the settling is approximately $4 \mathrm{~ms}$. While the initial transient response is comparable to the proportional control system, the integral action requires additional time to drive the steady-state error to zero. Of the three systems presented (open loop, proportional, integral-lead), only the integral-lead system can guarantee zero steady-state error in response to a constant input command, thus making it the most suitable choice for nanopositioning applications. 


\section{Proportional integral control for steady-state positioning} in a vacuum

Steady-state nanopositioning tests were run inside an SEM to provide a more accurate measurement of TIM displacement and to characterize its precision and repeatability. The vacuum environment inside the SEM slows the heat transfer dynamics of the TIM because there is no surrounding atmosphere through which heat can be conducted to the substrate [31], [43]. Additionally, the more aggressive low-pass second-order Butterworth filter with a $20 \mathrm{~Hz}$ roll-off frequency is required inside the harsh electrical environment of the SEM. The slower TIM dynamics and the aggressive low-pass filter introduce instability when using the integral-lead control. However, a simple proportional integral control,

$$
D(s)=k_{p}+\frac{k_{i}}{s}
$$

is sufficient because we are bandwidth limited to $20 \mathrm{~Hz}$ by the roll-off frequency of the aggressive low-pass filter we used to compensate for the noisy electrical environment inside the SEM.

\section{Position control results}

TIM positioning accuracy was quantified by measuring the displacement resulting from five input voltage levels. Once again the data was taken in random order and with sufficient replication to measure uncertainty. Regression analysis was used to identify an envelope that bounds, to a $95 \%$ confidence, TIM displacement as a function of input voltage. Figure 20 shows the open and closed-loop data points and their respective reduced 4th order regressions. The open and closed-loop regressions have $R^{2}$ values of 0.9999 and 0.9998 respectively.

Although the analysis is similar to that done on the regressions in Figures 8 and 10, this analysis relates displacement to the input voltage driving the system. The previous analysis related displacement to the output voltage of the PMT.

The spread of the bounding envelopes are a measure of the uncertainty in the experiment. Potential uncertainty comes from input voltage variation, displacement measurement, and device operation variability. Implementing feedback control affects the device operation while the input voltage and the displacement measurement remain the same. Comparing the spread of the bounding envelopes for the open and closedloop data sets reveals any significant effect feedback control has on TIM positioning accuracy.

The open-loop data is contained by an envelope with a maximum spread of $\pm 29.9 \mathrm{~nm}$ while the closed-loop data is bounded by an envelope with a maximum spread of $\pm 29.4 \mathrm{~nm}$. These values are close to each other indicating that the sensor did not introduce significant noise that would degrade the system accuracy. Displacement measurements taken on a device that was known to not be moving isolated the uncertainty in the SEM measurement process. The SEM measurements have a $95 \%$ confidence interval of $\pm 23.1 \mathrm{~nm}$. As this represents over $75 \%$ of the open and closed-loop positioning uncertainty, it is likely that the device performance is better than we can measure with this setup.

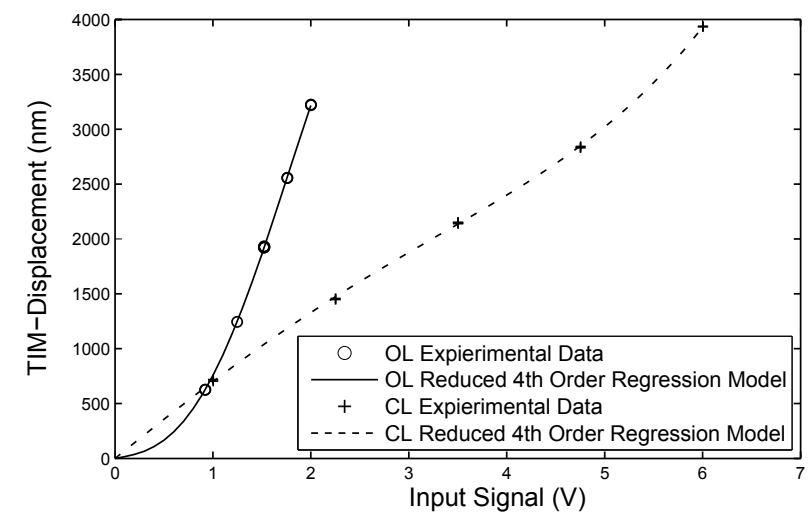

Fig. 20: Open-loop (OL) and closed-loop (CL) nanopositioning data and regression. (gain $\approx 400,20 \mathrm{~Hz}$ low-pass filtered)

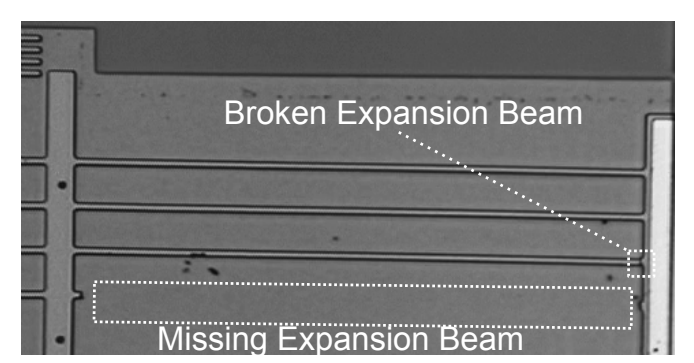

Fig. 21: Optical micrograph of a thermomechanical inplane microactuator with one missing and one broken expansion beam to introduce a disturbance.

\section{E. Disturbance rejection}

Disturbance rejection is another significant advantage from operating systems with feedback control. MEMS and other micro-scale devices are susceptible to normally insignificant environmental factors. Dust particles can impede motion, surface stiction can dominate other system forces, and delicate components can be easily fractured. The ability to automatically compensate for these complications will increase the reliability and robustness of many MEMS devices.

A TIM with one missing expansion beam and one broken expansion beam,as shown in Figure 21, was operated closed

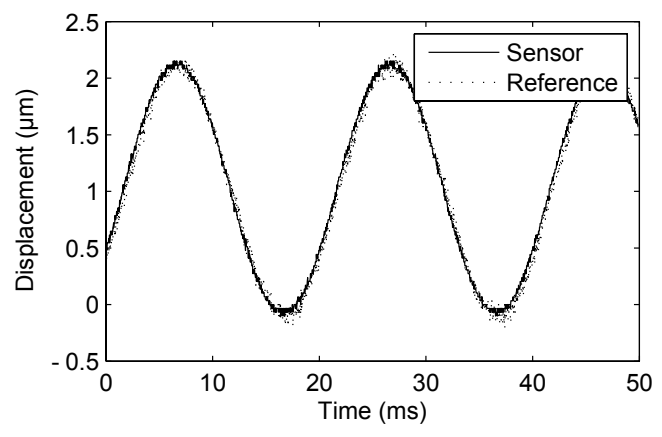

Fig. 22: Closed-loop response of the broken thermomechanical inplane microactuator (TIM) /piezoresistive microdisplacement transducer (PMT) system shown in Figure 21 (gain $=1000,37 \mathrm{kHz}$ low-pass filtered). The system demonstrating insensitivity to the significant defects. 
loop to demonstrate disturbance rejection. The same integral/lead controller, as described above, was used. Figure 22 is a plot of the input and output signals to the system. The excellent tracking, where the input and output signals are superimposed, demonstrates the system's insensitivity to the device defects.

\section{CONCLUSION}

It has been demonstrated that the PMT is an effective feedback sensor for closed-loop control of a MEMS thermal actuator. The PMT has a monotonically increasing mapping of output voltage to displacement, and a repeatability of $\pm 9.1 \mathrm{~nm}$.

Feedback control, using the PMT as the sensor, provided excellent tracking with no steady-state error, maintained the positioning resolution to $\pm 29 \mathrm{~nm}$ or less, and increased the robustness of the system such that it was insensitive to significant damage.

In a more general sense, the PMT demonstrates that uniformly doped, compliant, piezoresistive sensors can be used for both open-loop sensing and closed-loop control of MEMS actuators. Since such sensors are fabricated from the same material as the actuator to which they are coupled, no additional process steps are required to make such sensors an integral element of a MEMS actuator. Though the PMT was used with a TIM in this research, the broader concepts of an integrated piezoresistive sensor and the use of piezoresistance in feedback control can be extended to other MEMS actuators.

\section{ACKNOWLEDGEMENTS}

The authors would like to thank the reviewers for their suggestions on the development of the physics-based model of the experimental PMT response. The authors also gratefully acknowledge the support of the National Science Foundation through NSF grant CMS-0428532

\section{REFERENCES}

[1] B. Borovic, A. Liu, D. Popa, H. Cai, and F. Lewis, "Open-loop versus closed-loop control of mems devices: Choices and issues," Journal of Micromechanics and Microengineering, vol. 15, no. 10, pp. 1917 1924, 2005. [Online]. Available: http://dx.doi.org/10.1088/0960-1317/ $15 / 10 / 018$

[2] T. Hirano, L. Fan, W. Lee, J. Hong, W. Imaino, S. Pattanaik, S. Chan, P. Webb, R. Horowitz, S. Aggarwal, and D. Horsley, "High-bandwidth high-accuracy rotary microactuators for magnetic hard disk drive tracking servos," IEEE/ASME Transactions on Mechatronics, vol. 3, no. 3, pp. 156-165, 1998 .

[3] D. Horsley, N. Wongkomet, R. Horowitz, and A. Pisano, "Precision positioning using a microfabricated electrostatic actuator," IEEE Transactions on Magnetics, vol. 35, pp. 993-999, 1999.

[4] D. Horsley, R. Horowitz, and A. Pisano, "Microfabricated electrostatic actuators for hard disk drives," Proceedings of the IEEE Conference on Decision and Control, vol. 4, pp. 3120-3125, 2000.

[5] Y. Li and R. Horowitz, "Track-following controller design of MEMS based dual-stage servos in magnetic hard disk drives," Proceedings IEEE Conference on Robotics and Automation, vol. 1, pp. 953-958, 2000 .

[6] T. Semba, T. Hirano, J. Hong, and L. Fan, "Dual-stage servo controller for HDD using MEMS microactuator,' IEEE Transactions on Magnetics, vol. 35, no. 5, pt. 1, pp. 2271-2273, 1999

[7] Y. Sun, K. Piyabongkam, A. Sezen, B. Nelson, R. Rajamani, R. Schoch, and D. Potasek, "A novel dual-axis electrostatic microactuation system for micromanipulation," IEEE International Conference on Intelligent Robots and Systems, vol. 2, pp. 1796-1801, 2002.
[8] S. Lyshevski, "Nonlinear Microelectromechanical Systems (MEMS) analysis and design via the Lyapunov stability theory," Proceedings of the IEEE Conference on Decision and Control, vol. 5, pp. 4681-4684, 2001.

[9] M. S.-C. Lu and G. K. Fedder, "Position control of parallelplate microactuators for probe-based data storage," Journal of Microelectromechanical Systems, vol. 13, no. 5, pp. 759 - 769, 2004. [Online]. Available: http://dx.doi.org/10.1109/JMEMS.2004.835761

[10] S. Bhansali, A. L. Zhang, R. B. Zmood, P. E. Jones, and D. K. Sood, "Prototype feedback-controlled bidirectional actuation system for mems applications," Journal of Microelectromechanical Systems, vol. 9, no. 2, pp. 245 - 251, 2000. [Online]. Available: http://dx.doi.org/10.1109/84.846705

[11] M. Pai and N. C. Tien, "Operating principles of an electrothermal vibromotor for optical switching applications," Proceedings of SPIE The International Society for Optical Engineering, vol. 3878, pp. 124 - 130, 1999. [Online]. Available: http://dx.doi.org/10.1117/12.361253

[12] M. Daneman, N. Tien, O. Solgaard, A. Pisano, K. Lau, and R. Muller, "Linear microvibromotor for positioning optical components," Microelectromechanical Systems, Journal of, vol. 5, no. 3, pp. 159-165, 1996.

[13] J. C. Chiou and W. T. Lin, "Variable optical attenuator using a thermal actuator array with dual shutters," Optics Communications, vol. 237, no. 4-6, pp. 341-350, July 2004.

[14] B. Kim and K. Chun, "Fabrication of an electrostatic track-following micro actuator for hard disk drives using SOI wafer," J. Micromech. Microeng, vol. 11, no. 1, pp. 1-6, 2001

[15] P. Cheung, R. Horowitz, and R. Howe, "Design, fabrication, position sensing, and control of an electrostatically-driven polysilicon microactuator," IEEE Transactions on Magnetics, vol. 32, pp. 122-128, 1996.

[16] N. Maluf, An Introduction to Microelectromechanical Systems Engineering. Norwood, MA: Artech House, 2000.

[17] W. P. Eaton, "Surface micromachined pressure sensors," Ph.D. dissertation, The University of New Mexico, Albuquerque, New Mexico, May 1997.

[18] L. Cao, T. S. Kim, J. Zhou, S. C. Mantell, and D. L. Polla, "Calibration technique for MEMS membrane type strain sensors," Biennial University/Government/Industry Microelectronics Symposium - Proceedings, pp. 204 - 210, 1999. [Online]. Available: http: //dx.doi.org/10.1109/UGIM.1999.782854

[19] H. Joseph, B. Swafford, and S. Terry, "MEMS in the medical world," Sensors, vol. 14, no. 4, pp. 47-51, 1997.

[20] R. Schellin and G. Hess, "Silicon subminiature microphone based on piezoresistive polysilicon strain gauges," Sensors and Actuators, vol. 32, no. 1-3, pp. 555-559, 1992.

[21] C. S. Smith, "Piezoresistance effect in germanium and silicon," Physical Review, vol. 94, pp. 42-49, 1954.

[22] V. Gridchin and V. Lubimsky, "Phenomenological model of the piezoresistive effect in polysilicon films," Russian Microelectronics, vol. 32, no. 4, pp. 205-213, 2003.

[23] G. K. Johns, L. L. Howell, B. D. Jensen, and T. W. McLain, "A model for predicting the piezoresistive effect in microflexures experiencing bending and tension loads," Journal of Microelectromechanical Systems, vol. 16, no. 1, pp. 226-235, February 2008.

[24] L. Ristic, R. Gutteridge, B. Dunn, D. Mietus, and P. Bennett, "Surface micromachined polysilicon accelerometer," Solid-State Sensor and Actuator Workshop, 1992. 5th Technical Digest., IEEE, pp. 118 - 121, 1992. [Online]. Available: http://dx.doi.org/10.1109/SOLSEN. 1992.228311

[25] K. Kwon and S. Park, "Three axis piezoresistive accelerometer using polysilicon layer," International Conference on Solid-State Sensors and Actuators, Proceedings, vol. 2, pp. 1221 - 1224, 1997.

[26] H. Guckel, "Surface micromachined pressure transducers," Sensors and Actuators A, vol. 28, pp. 133-146, 1991.

[27] PolyMUMPs Design Handbook, MEMSCAP Inc., 2005. [Online]. Available: www.memsrus.com/documents/PolyMUMPs.DR.v11.pdf

[28] SUMMiT V - Five Level Surface Micromachining Technology Design Manual, 1st ed., MEMS Device and Reliability Physics Department, Microelectronics Development Laboratory, Sandia National Laboratories, PO Box 5800, Albuquerque, NM 87185, 22 September 2005. [Online]. Available: www.sandia.gov/mstc/education/alliance/ tools/SUMMiT_V_Dmanual_V1.3_MASTER_external.pdf

[29] R. Cragun, "Constrained thermal expansion micro-actuator," ASME Dyn Syst Control Div Publ DSC, vol. 66, no. 365 - 371, pp. 365-371, 1998.

[30] L. Que, A. Otradovec, and Y. Gianchandani, "Pulse and DC operation lifetimes of bent-beam electrothermal actuators," Proceedings of the IEEE Micro Electro Mechanical Systems (MEMS), pp. 570-573, 2001. 
[31] C. Lott, T. W. McLain, J. N. Harb, and L. L. Howell, "Modeling the thermal behavior of a surface-micromachined linear-displacement thermomechanical microactuator," Sensors and Actuators, vol. 101, no. 1-2, pp. 239-250, 2002.

[32] A. A. Geisberger, N. Sarkar, M. Ellis, and G. D. Skidmore, "Electrothermal properties and modeling of polysilicon microthermal actuators," Journal of Microelectromechanical Systems, vol. 12, no. 4, pp. 513523, August 2003.

[33] R. Hickey, D. Sameoto, T. Hubbard, and M. Kujath, "Time and frequency response of two-arm micromachined thermal actuators," Journal of Micromechanics and Microengineering, vol. 13, pp. 40-46, 2002.

[34] J. H. Comtois, V. M. Bright, and M. W. Phipps, "Thermal microactuators for surface-micromachining processes," Proceedings of SPIE - The International Society for Optical Engineering, vol. 2642, pp. 10 - 21, 1995.

[35] L. L. Chu, L. Que, A. D. Oliver, and Y. B. Gianchandani, "Lifetime studies of electrothermal bent-beam actuators in single-crystal silicon and polysilicon," Journal of Microelectromechanical Systems, vol. 15, no. 3, pp. 498-506, June 2006.

[36] M. S. Baker and L. L. Howell, "On-chip actuation of an in-plane compliant bistable micro-mechanism," Journal of Microelectromechanical Systems, vol. 11, no. 5, pp. 566-573, 2002.

[37] B. D. Jensen and L. L. Howell, "Identification of compliant pseudo-rigidbody mechanism configurations resulting in bistable behavior," Jornal of Mechanical Design, vol. 125, no. 4, pp. 701-708, December 2003.

[38] N. D. Masters and L. L. Howell, "A self-retracting fully-compliant bistable micromechanism," Journal of Microelectromechanical Systems, vol. 12, no. 3, pp. 273-280, 2003.

[39] C. Lee, Y.-S. Lin, Y.-J. Lai, M. H. Tasi, C. Chen, and C.-Y. Wu, "3$\mathrm{V}$ driven pop-up micromirror for reflecting light toword out-of-plane direction for VOA applications," IEEE Photonics Technology Letters, vol. 16, no. 4, pp. 1044-1046, April 2004.

[40] L. Que, K. Udeshi, J. Park, and Y. B. Gianchandani, "A bistable electrothermal RF switch for high power applications," Proceedings of the IEEE Micro Electro Mechanical Systems (MEMS), pp. 797-800, 2004.

[41] Y. Wang, Z. Li, D. T. McCormick, and N. C. Tien, "A low-voltage lateral MEMS switch with high RF performance," Journal of Microelectromechanical Systems, vol. 13, no. 6, December 2004.

[42] N. B. Hubbard and L. L. Howell, "Experimental repeatability of a thermal actuator for nanopositioning," American Society of Mechanical Engineers, Micro-Electro Mechanical Systems Division, (Publications) MEMS, pp. 427 - 430, 2004.

[43] R. K. Messenger, T. W. McLain, and L. L. Howell, "Improved nanopositioning resolution through piezoresistive feedback control of a MEMS thermal actuator," American Society of Mechanical Engineers, Dynamic Systems and Control Division (Publication) DSC, vol. 74 DSC, no. 2 PART B, pp. 1327 - 1334, 2005.

[44] R. K. Messenger, "Modeling and control of surface micromachined thermal actuators," Master's thesis, Brigham Young University, August 2004. [Online]. Available: http://contentdm.lib.byu.edu/ETD/image/ etd434.pdf

[45] R. K. Messenger, T. W. McLain, and L. L. Howell, "Feedback control of a thermomechanical inplane microactuator using piezoresistive displacement sensing," American Society of Mechanical Engineers, Dynamic Systems and Control Division (Publication) DSC, vol. 73, no. 2 PART B, pp. $1301-1310,2004$.

[46] L. Lin and M. Chiao, "Electrothermal responses of lineshape microstructures," Sensors and Actuators, vol. 55, pp. 35-41, 1996.

[47] J. Wittwer, M. Baker, and L. Howell, "Simulation, measurement, and asymmetric buckling of thermal microactuators," Sensors \& Actuators: A. Physical, vol. 128, no. 2, pp. 395-401, 2006.

[48] Y. Kanda, "A graphical representation of the piezoresistance coefficients in silicon," Electron Devices, IEEE Transactions on, vol. 29, no. 1, pp. 64-70, January 1982.

[49] T. L. Waterfall, G. K. Johns, R. K. Messenger, B. D. Jensen, T. W McLain, and L. L. Howell, "Observations of piezoresistivity for polysilicon in bending that are unexplained by current models," Sensors and Actuators A: Physical, vol. 141, no. 2, pp. 610-618, 2008.

[50] R. K. Messenger, "Integrated piezoresistive sensing for feedback control of compliant MEMS," Ph.D. dissertation, Brigham Young University, October 2007. [Online]. Available: http://contentdm.lib.byu.edu/ETD/ image/etd2115.pdf

[51] P. Kleimann, B. Semmache, M. Le Berre, and D. Barbier, "Thermal drift of piezoresistive properties of lpcvd polysilicon thin films between room temperature and 200 c," Materials Science \& Engineering B, vol. 46, no. $1-3$, pp. $43-46,1997$.
[52] J. Lawson and J. Erjavec, Modern Statistics for Engineering and Quality Improvement, 1st ed. Duxbury, 2001, ISBN 0 534-19050-2.

[53] R. K. Messenger, T. W. McLain, and L. L. Howell, "Piezoresistive feedback for improving transient response of mems thermal actuators," Proceedings of SPIE - The International Society for Optical Engineering, vol. 6174 I, pp. 617408 -, 2006. [Online]. Available: http://dx.doi.org/10.1117/12.657954

[54] G. F. Franklin, J. D. Powell, and A. Emami-Naeini, Feedback control of dynamic systems, 3rd ed. Addison Wesley, 1995.

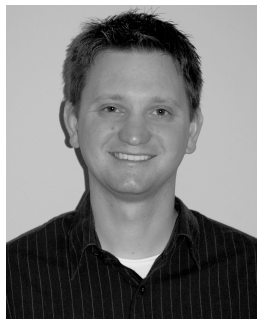

Robert K. Messenger received the B.S., M.S. and Ph.D. degrees in mechanical engineering from Brigham Young University, Provo, UT, in 1999, 2004, and 2007. His research efforts focused on feedback control of compliant MEMS devices. He currently works as a thermal/fluidic architect in Technology Development Operations for HP in Corvallis, OR. His research interests include thermal inkjet printing, piezoresistive MEMS sensing, microscale system dynamics, and feedback control.

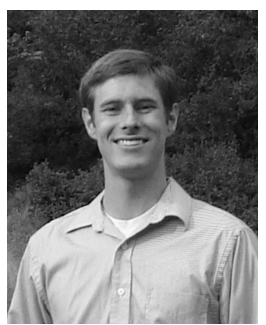

Quentin T. Aten is a Ph.D. candidate at Brigham Young University (BYU), Provo, UT. He received his B.S. and M.S. degrees in mechanical engineering from BYU in 2007 and 2008. During his undergraduate degree, he contributed to the feedback control of piezoresistively controlled microelectromechanical systems (MEMS) thermal actuators. His graduate research focuses on compliant MEMS mechanisms, with specific application to bioMEMS devices for genetically transforming living cells.

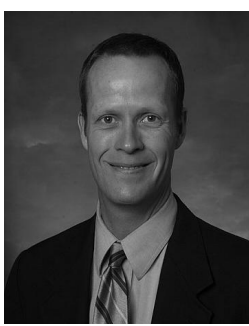

Timothy W. McLain is a professor in the Department of Mechanical Engineering at Brigham Young University (BYU) where he currently holds the position of department chair. After completing his B.S. and M.S. degrees at BYU, he worked for two years with Sarcos, Inc. in Salt Lake City on the modeling and control of fluid-power systems for robotics applications. While completing his Ph.D. work at Stanford University, Professor McLain worked with the Monterey Bay Aquarium Research Institute on the control of underwater robotic vehicles. Since joining BYU in 1995, he has been involved in the modeling and control of hydraulic actuation systems and microelectromechanical systems (MEMS). During the summers of 1999 and 2000, he was a visiting scientist at the Air Force Research Laboratory where he initiated research in the cooperative control of unmanned air vehicles (UAVs). Since that time, he has pursued research involving the modeling and control of miniature UAVs, real-time trajectory generation for UAVs, and cooperative control of UAV teams. Professor McLain is a senior member of IEEE, an Associate Fellow of AIAA and has served as a member of the AIAA Unmanned Systems Program Committee. 


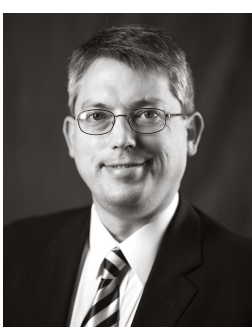

Larry L. Howell is a Professor and past chair of the Department of Mechanical Engineering at Brigham Young University (BYU), where he holds a University Professorship. Prof. Howell received his B.S. degree from Brigham Young University in 1987 and his M.S. and Ph.D. degrees from Purdue University in 1991 and 1993. Prior to joining BYU in 1994 he was a visiting professor at Purdue University, a finite element analysis consultant for Engineering Methods, Inc., and an engineer on the design of the YF-22 (the prototype for the U.S. Air Force F-22). He is a Fellow of ASME, past chair of the ASME Mechanisms \& Robotics Committee, and an associate editor for the Journal of Mechanical Design. He is the recipient of the ASME Mechanisms \& Robotics Award, an NSF CAREER Award, the ASME Design Automation Conference Best Paper Award, BYU Technology Transfer Award, and the Maeser Research Award. Prof. Howell's patents and technical publications focus on compliant mechanisms and microelectromechanical systems. He is the author of the book Compliant Mechanisms published by John Wiley \& Sons. 